\title{
$\$$ Research Square

\section{Near-atomic size highly positive silver nanoparticles are bactericidal targeting cell wall and adherent fimbriae expression}

Lok Pokhrel ( $\square$ pokhrell18@ecu.edu )

East Carolina University https://orcid.org/0000-0002-4606-9973

Zachary Jacobs

School of Law, University of California, Berkeley

Dmitriy Dikin

Department of Mechanical Engineering, College of Engineering, Temple University

Shaw Akula

Department of Microbiology and Immunology, The Brody School of Medicine, East Carolina University

\section{Article}

Keywords: Novel antimicrobial, Nosocomial infections, metal nanoparticles, healthcare associated infections, Nanotoxicology

Posted Date: September 1st, 2021

DOl: https://doi.org/10.21203/rs.3.rs-848672/v1

License: (9) (1) This work is licensed under a Creative Commons Attribution 4.0 International License. Read Full License 


\section{Abstract}

To tackle growing antibiotic resistance (AR) and hospital-acquired infections (HAls), novel antimicrobials are warranted that are effective against HAls and safer for human use. We hypothesize that near-atomic size positively charged silver nanoparticles (AgNPs) could specifically target bacterial cell wall and adherent fimbriae expression, serving as the next generation antimicrobial agent. Herein we show positively charged, $5 \mathrm{~nm} \mathrm{NH} \mathrm{H}_{2}$-AgNPs were bactericidal; negatively charged, $45 \mathrm{~nm}$ Citrate-AgNPs were nontoxic, and $\mathrm{Ag}^{+}$ions were bacteriostatic forming honeycomb-like potentially resistant phenotype, at $10 \mu \mathrm{g} \mathrm{Ag} / \mathrm{mL}$ in E. coli dh5a. Further, adherent fimbriae were expressed with Citrate-AgNPs, whereas $\mathrm{NH}_{2}$-AgNPs $(0.5-10 \mu \mathrm{g} / \mathrm{mL})$ or $\mathrm{Ag}^{+}$ions $(10 \mu \mathrm{g} / \mathrm{mL})$ inhibited fimbriae expression. Potent bactericidal effects demonstrated by biocompatible $\mathrm{NH}_{2}-\mathrm{AgNPs}$ and the lack of toxicity of Citrate-AgNPs lend credence to the hypothesis that near-atomic size, positively charged AgNPs may serve as a nextgeneration antibacterial agent, potentially addressing the rising HAls and patient health and safety.

\section{Main Text}

Hospital-acquired infections (HAls), synonymously called nosocomial infections, are detrimental to patient safety and recovery. HAls are a threat in all hospitals, but the intensive care unit (ICU) documents the highest HAI rates ${ }^{1}$. Moreover, HAls are most common with the central line bloodstream and ventilator usage costing an extra 9.5 and 9.1 days of hospital stay, respectively ${ }^{2}$. Annually, over 12 million deaths occur due to HAls globally, of which $95 \%$ occur in low- and middle-income countries (LMICs) ${ }^{3}$. In the United States alone, over 2 million infections are caused by HAls, particularly associated with antibiotic resistance (AR) and/or multidrug-resistant organisms (MDROs), of which about 23,000 fatalities occur, annually ${ }^{2}$.

Gram-negative bacteria are considered more resistant to current antibiotics compared to gram-positive bacteria mainly due to the presence of cell wall that limits the uptake of antibiotics in the former and is lacking in the latter ${ }^{4}$. Escherichia coli is among the gram-negative bacteria commonly causing HAls ${ }^{5}$, including food-borne outbreaks ${ }^{6}$, and ultimately deaths ${ }^{5}$. In virulent strains such as E. coli 01:K1:H7 (CN1018), expression of adherent fimbriae has been associated with increased bacterial survival and inflammatogenic response in the urinary tract infection mouse model ${ }^{7}$. Moreover, bacterial isolates lacking expression of fimbriae have demonstrated reduced growth, adhesion, biofilm formation and virulence, thereby resulting in low infections and improved survival in animal models and humans when infected with the virulent strains ${ }^{8}$. Hence, a need for better antimicrobial agents that can specifically target the cell wall and/or adherent fimbriae expression cannot be overstated, and engineered nanomaterials (ENMs) may have the potential to serve as the next generation antimicrobial agent ${ }^{9}$.

ENMs are being used in various commercial applications (e.g., fabric, mask, medical device, paint, cement, etc.), but the potential factors and mechanisms underpinning their antimicrobial activities have remained unclear ${ }^{10-12}$ as results are largely compounded by the heterogeneity of the ENMs used, 
endpoints measured, and differential sensitivity of the bioassays used. As the studies on the actual mode of ENM toxicity is ongoing, recent literature suggest that the capping ligand, core particle size, and surface charge likely play a role ${ }^{13-17}$. In the recent rule published by the USEPA under TSCA (Toxic Substances Control Act), the roles of inherent particle attributes, including the particle size, surface charge (measured as zeta potential), aggregation state, or surface reactivity on ENM toxicity, were emphasized as factors commonly linked to nanotoxicity ${ }^{18}$. Necessary for future endeavors is an understanding of desired 'nano' properties, so certain characteristics may be wishfully tailored to render ENM safer (e.g., for environmental remediation), or more toxic (e.g., for neutralizing AR/MDROs).

Molecular or atomic scale interactions occurring at the nanoscale was previously difficult to ascertain optically owing to the Abbe diffraction ${ }^{19}$. Nonetheless, routine use of electron microscopy in tandem with surface analytical spectroscopic techniques have now enabled researchers to track individual NPs on the cell surface and its interior (cytoplasm and nucleus). Recently, Werner and colleagues ${ }^{19}$ asserted that "it would be advantageous to require the nanomaterial to be as minimally specific as necessary in order to act as delivery vector, nanosensor, or imaging agent." This is crucial given that a given NP has several physico-chemical properties, among which only a few characteristics are routinely measured, including particle size, zeta potential, surface linker, aggregation, etc. Adhering to the 'Occam's razor', also called 'philosophy of parsimony' 20 , a minimal set of defined physicochemical properties of ENMs that are/can be routinely measured may enable designing ENMs for desired applications such as treating the HAls. Herein, employing two different sizes AgNPs ( $5 \mathrm{~nm}$ versus $45 \mathrm{~nm}$ ) with high contrasting surface charges (high positive versus high negative), including dissolved ionic $\mathrm{Ag}^{+}$as positive control, this study aimed at: (1) elucidating potential factors and mechanisms influencing nano-bio interactions and toxicity in E. coli, a common gram-negative bacillus with high AR/MDR potential; (2) using this information, determining the most potent antibacterial AgNPs; and (3) documenting potential phenotypic plasticity (i.e., shape-shifting) in $E$. coli in response to different silver treatments.

Purified AgNPs were characterized using the TEM and images were analyzed using an ImageJ. Average TEM diameter of the $\mathrm{NH}_{2}$-AgNPs was $5.8 \pm 2.8 \mathrm{~nm}$, and were spherical in shape, crystalline, and had a high positive average zeta potential of $+41.6 \mathrm{mV}$ due to the cationic amino groups on the NP surface (Fig. 1; Table 1). The uniform $\mathrm{NH}_{2}$ - coating thickness on the surface of AgNPs was measured in the range 0.5$1.5 \mathrm{~nm}$, thereby enabling AgNPs' stability via electrosteric repulsion. Average TEM diameter of CitrateAgNPs was $44.8 \pm 5.0 \mathrm{~nm}$, and were pseudospherical in shape, crystalline, and had a high negative average zeta potential of $-30 \mathrm{mV}$ due to the anionic carboxyl groups on the NP surface (Fig. 1; Table 1). The uniform citrate-coating thickness on the surface of AgNPs was $1.8 \mathrm{~nm}$, which enabled NPs stability via electrostatic stabilization. Further, TEM analysis of AgNPs morphology suggests that both the $\mathrm{NH}_{2}{ }^{-}$ and citrate- ligands could effectively confer stability to AgNPs by preventing aggregation, and thus the nano-suspensions were observed to be highly stable in aqueous suspension over several years. Dynamic light scattering (DLS) analysis of average hydrodynamic diameter (HDD) for $\mathrm{NH}_{2}-\mathrm{AgNPs}$ was $4.3 \mathrm{~nm}$ and $11 \mathrm{~nm}$ for Citrate-AgNPs. UV-Vis spectrophotometry analysis showed localized surface plasmon resonance $\left(\lambda_{\max }\right)$ at $416.5 \mathrm{~nm}$ for $\mathrm{NH}_{2}-$ AgNPs, and $425 \mathrm{~nm}$ for Citrate-AgNPs, and that dilution 
(Supplementary Information Fig. S1), incubation time $(72 \mathrm{~h})$ and temperature $\left(35^{\circ} \mathrm{C}\right)$ had no effect on the stability of both the AgNPs (Supplementary Information Table S2).

Our results showed that $E$. coli population increased over the $72 \mathrm{~h}$ period for the negative controls (Fig. 2). Citrate-AgNPs ( 0.5 or $10 \mu \mathrm{g} / \mathrm{mL}$ ), or $\mathrm{Ag}^{+}$ions particularly at $0.5 \mu \mathrm{g} / \mathrm{mL}$, also showed positive cell growth $\left(\mathrm{OD}_{600}>0.6\right.$ a.u.) over $72 \mathrm{~h}$. However, exposure to $10 \mu \mathrm{g} / \mathrm{mL} \mathrm{NH} \mathrm{H}_{2}-$ AgNPs showed, after initial acclimation, a steady decline in E. coli growth with population completely crashing by $72 \mathrm{~h}$, confirming a bactericidal effect of $\mathrm{NH}_{2}-$ AgNPs at $10 \mu \mathrm{g} / \mathrm{mL}$ (Fig. 2). Exposure to $10 \mu \mathrm{g} / \mathrm{mL} \mathrm{Ag}^{+}$ion demonstrated strong bacteriostatic effect (Fig. 2). Further, at $0.5 \mu \mathrm{g} / \mathrm{mL} \mathrm{NH}_{2}-$ AgNPs inhibited bacteria growth more effectively than the same concentration of Citrate-AgNPs or $\mathrm{Ag}^{+}$ions (Fig. 2). Taken together, these results indicate that $\mathrm{NH}_{2}-\mathrm{AgNPs}$ possess strong bactericidal activity, while $\mathrm{Ag}^{+}$ions demonstrated strong bacteriostatic effect, at $10 \mu \mathrm{g} \mathrm{Ag} / \mathrm{mL}$ level.

Potential interaction with the bacterial cell wall upon physical contact with NPs is a plausible explanation for antibacterial effects of AgNPs ${ }^{12}$. Small size (5 nm diameter) AgNPs could competitively interact with bacterial cell wall due to electrostatic attraction (Fig. 4A). Further, high positively charged cationic AgNPs (with amino $\left[-\mathrm{NH}_{2}{ }^{+}\right]$as surface ligand) demonstrated higher affinity to bacterial cell surface binding compared to the negatively charged AgNPs (with citrate [-COO] moiety) (Figs. 3 and 4).

We further assessed if $E$. coli cell diameter is a predictor of cell length using the General Linear Model. Results showed that cell diameter is a strong predictor of cell length (Supplementary Information Table S3). Plotting cell diameter versus cell length (Fig. 2B, C) revealed distinct cell clusters reflecting differing cell morphologies. Cells treated with $10 \mu \mathrm{g} / \mathrm{mL} \mathrm{Ag}^{+}$ions demonstrated change in cell morphology from individual rod-shape to hexagonal honeycomb-like clusters of cells stacking together (Figs. 3F, 5). Such hexagonally stacked honeycomb phenotype is known to minimize surface area to volume ration, thereby significantly reducing available exposure surfaces per bacterial cell to the stressor, and in this case, $\mathrm{Ag}^{+}$ ions at $10 \mu \mathrm{g} / \mathrm{mL}^{21}$. Moreover, it has been suggested that hexagonal honeycomb structure, as observed in beehives, is likely the most economically feasible shape in terms of material and energy expended to form or build the honeycomb 22 . To our knowledge, this is the first study to report a honeycomb-like, potentially resistant cell phenotype in gram-negative $E$. coli upon $\mathrm{Ag}^{+}$ions exposure. At $10 \mu \mathrm{g} / \mathrm{mL} \mathrm{NH}{ }_{2}^{-}$ AgNPs treatment, E. coli survival severely diminished before the population completely crashed by $72-\mathrm{h}$ as verified by FE-SEM analysis (i.e., no cell could be located in the samples under the FE-SEM). This result confirms potent bactericidal effects of $\mathrm{NH}_{2}-\mathrm{AgNPs}$ at $10 \mu \mathrm{g} \mathrm{Ag} / \mathrm{mL}$, thereby avoiding the evolution of potentially resistant phenotype as observed for $\mathrm{Ag}^{+}$ions.

It was recently documented that bacteria could form lenticular shaped chains upon metal stress. Chakravarty \& Banerjee ${ }^{21}$ studied morphological changes in Acidiphilium symbioticum $\mathrm{H} 8$ upon exposure to $\mathrm{Cu}$ (as $500 \mathrm{mM} \mathrm{CuSO}_{4}$ ) and $\mathrm{Cd}\left(\right.$ as $12.5 \mathrm{M} \mathrm{CdSO}_{4}$ ) and found that loosely packed coccobacillus-type cells (short rod-shaped) transformed into round shape and were highly packed 
together upon exposure to the metals. Likewise, Khusro et al. ${ }^{23}$ noted similar stress response induced in Bacillus subtilis KPA upon exposure to mercuric chloride, wherein treated cells presented round phenotype from the native rod-shape.

Because bacteria exposed to $10 \mu \mathrm{g} / \mathrm{mL} \mathrm{NH}_{2}-$ AgNPs for $72 \mathrm{~h}$ did not survive and thus the cells could not be located under the SEM, we then briefly exposed the bacteria for 10 min to the same concentration (10 $\mu \mathrm{g} / \mathrm{mL}$ ) of $\mathrm{NH}_{2}-$ AgNPs and mapped AgNPs-cell interaction, potential cell wall damage, and elemental Ag validation across the selected areas as shown in Fig. 4. SEM analysis of the bacterial cells did not reveal morphological damage, but a larger particulate of Ag (size range 155-157 nm in diameter) was clearly found to be located at the end of each cell (see Energy Dispersive Spectroscopy [EDS] spectra \#10 and \#11 in Fig. 4). It was previously shown that smaller size and positively charged AgNPs are relatively more toxic that the larger size and negatively charged $\mathrm{AgNPs}^{12}$, but the $\mathrm{NH}_{2}-\mathrm{AgNPs}^{\prime}$ localization at the end of E. coli cells has been for the first time clearly imaged in this study at high resolution using the STEM mode. It can thus be inferred that $5 \mathrm{~nm}$ diameter, highly positively charged $\mathrm{NH}_{2}-\mathrm{AgNPs}$ precipitated upon electrostatic interactions with the bacterial cell surfaces and/or biomolecules within the cell exterior, thereby forming larger particulates of Ag ranging in diameter 155-157 nm (Fig. 4A). Furthermore, high positively charged $\mathrm{NH}_{2}-$ AgNPs attachment to the bacterial cell surface may lead to "hyperpolarization" of the cell wall, more specifically, peptidoglycan that makes up the cell wall, as described recently for gold nanoparticle interactions with $E$. coli $\mathrm{K} 12^{24}$, subsequently leading to adherent fimbriae inhibition and cell wall damage as observed in our study (Fig. 4, Table 2).

EDS surface elemental mapping of E. coli exposed to $10 \mu \mathrm{g} / \mathrm{mL} \mathrm{Ag}^{+}$ions for $72 \mathrm{~h}$ showed a greater amount of silver on the cell surface and were found associated with common biological elements such as $\mathrm{C}, \mathrm{O}, \mathrm{Na}, \mathrm{K}, \mathrm{Cl}$, (Fig. 5). In comparison, E. coli exposed to $10 \mu \mathrm{g} / \mathrm{mL}$ Citrate-AgNPs for $72 \mathrm{~h}$ confirmed the above toxicity results showing lesser amount of silver on the cell surface and were found associated with such biological elements: C, O, Na, K, and Cl but not with P and S (Supplementary Information Fig. S2).

In E. coli dh5a, mannose resistant Proteus-like [MR/P]) fimbriae are expressed ${ }^{7}$. FE-SEM image analysis revealed the presence of filamentous adherent fimbriae in the negative control group, including in both concentrations of Citrate-AgNPs and low concentration $\left(0.5 \mu \mathrm{g} / \mathrm{mL}\right.$ ) of $\mathrm{Ag}^{+}$ions (Fig. 3; Table 2). However, adherent fimbriae were completely absent in $E$. coli when treated with $\mathrm{NH}_{2}-\mathrm{AgNPs}_{\mathrm{N}}$ at both concentrations $(0.5$ and $10 \mu \mathrm{g} / \mathrm{mL})$, changing them into non-motile phenotype (Fig. 4; Table 2). Fimbriae were also absent with $\mathrm{Ag}^{+}$ions treatment, particularly, at $10 \mu \mathrm{g} / \mathrm{mL}$, when bacteria changed their morphology to hexagonal honeycomb-like phenotype (Fig. 3F; Table 2). Fimbriae expression in pathogenic bacterial strains such as $E$. coli is known to promote adhesion to substrates, biofilm formation, and virulence, causing higher infections and reduced survival in animals and humans ${ }^{7,8}$.

Particle size vis-à-vis material-specific properties could govern nano-bio interactions ${ }^{12,13,19}$. Previous studies that modeled artificial phospholipid bilayer interacting with rod-like biomolecules suggest that the 
energy on the surface may influence surface molecule-cell membrane association, potentially leading to cell entry of biomolecules ${ }^{26,27}$ and toxicity. Energy barrier that exists between NPs and the biologic surfaces ought to be overcome ${ }^{28}$ before the NPs could interact with the receptor surfaces (cell wall or cell membrane). In our study, a remarkable difference in the magnitude of surface charge between the $5 \mathrm{~nm}$ $\mathrm{NH}_{2}$-AgNPs $(\mathrm{z}=+41.6 \mathrm{mV})$ and $45 \mathrm{~nm}$ Citrate-AgNPs $(\mathrm{z}=-30 \mathrm{mV})$ can be attributed to higher attraction forces between the $E$. coli surface and the $\mathrm{NH}_{2}-$ AgNPs surface (Table 1), enabling direct physical contact between the two surfaces (as evidenced by EDS spectra showing particulates of silver on the $E$. coli surfaces; see Fig. 4), leading to increased cell death after $4 \mathrm{~h}$ followed by complete population collapse by $72 \mathrm{~h}$. On the other hand, a significantly lower charge difference observed for Citrate-AgNPs suggests that the dominant repulsive forces (lower attraction; Table 1) could have played a key role in keeping most of the Citrate-AgNPs away from the biologic surfaces (as confirmed by EDS elemental mapping showing lower amount of silver on E. colisurfaces) and this might explain the lowest toxicity observed for Citrate-AgNPs (Figs. 2, 3C,D; Supplementary Information Fig. S2). Evidence from previous studies also corroborate a potential for direct physical interactions between the NPs (e.g., graphene and derivatives) and the biologic receptors ${ }^{29,30}$, suggesting direct physical interaction may serve as a primary mechanism explaining AgNP toxicity.

Shape-and size-shifting in E. coli have been known to occur in response to varied environmental stressors. It is hypothesized that bacteria can shrink or assume spherical (from originally rod-like) shape to minimize cell surface area when conditions become more stressful. Liu et al. ${ }^{31}$ investigated potential effects of ZnONPs (diameter $70 \pm 15 \mathrm{~nm}$ ) in E. coli and observed deformed cell membranes that led to cell leakage but did not observe any morphological changes. In another study, AgNPs could potentially penetrated into $E$. coli cells, resulting in membrane degradation ${ }^{32}$. At $24 \mathrm{~h}$ post-exposure, a significant growth inhibition was recorded as a function of AgNPs concentrations ${ }^{32}$. Formation of irregular-shaped pits in the outer membrane was attributed to inhibition in cell growth and reproduction. Further, increased AgNPs concentration resulted in smaller bacterial size ${ }^{32}$. He et al. ${ }^{33}$ treated E. coli with MgONPs with an average size of $20 \mathrm{~nm}$. Using SEM, the authors revealed disrupted membranes in E. coli exposed to $20 \mathrm{~nm}$ MgONPs, that led to the rough and leaky E. coli cells ${ }^{33}$. Measuring the average roughness of bacteria using atomic force microscopy before and after Catechin-CuNPs ( $5 \mathrm{~nm}$ diameter) treatments, Li et al. ${ }^{34}$ found that the untreated $E$. coli cell roughness was $6.32 \mathrm{~nm}, 4.88 \mathrm{~nm}(\mathrm{Rq}, \mathrm{Ra})$, whereas for the treated cells the roughness increased significantly to $71.6 \mathrm{~nm}, 57.3 \mathrm{~nm}$ (Rq, Ra); and for Streptococcus aureus the roughness increased from $4.51 \mathrm{~nm}, 3.13 \mathrm{~nm}(\mathrm{Rq}, \mathrm{Ra})$ to $76.1 \mathrm{~nm}, 59.9 \mathrm{~nm}(\mathrm{Rq}$, $\mathrm{Ra}$ ). Such evidence strongly support the premise that NPs (e.g., Catechin-CuNPs) can potentially disrupt the basic cell membrane structure (i.e., form) and consequently the membrane functions ${ }^{34}$.

Understanding NP-induced oxidative stress in human cells is key in developing potent antibacterial that is also biocompatible for human use. Reactive oxygen species (ROS) may be generated upon NP exposure. Lipid peroxidation occurs when excess ROS affects cell membranes and can also lead to oxidation and denaturation of proteins and DNA damage, further inducing inflammatory immune responses and cell 
death $^{35}$. Our results show no lipid peroxidation (MDA) in human lung epithelial (H-6053; Cell Biologics) and dermal fibroblast (106-05A-1526; Millipore Sigma) cells upon $\mathrm{NH}_{2}-$ AgNPs treatments as the MDA levels were all below the background concentrations (negative control, dilution buffer). Rather, data revealed a decrease in MDA with up to $10 \mu \mathrm{g} / \mathrm{ml}$ of $\mathrm{NH}_{2}-$ AgNPs treatments in lung cells compared to treatments with the negative control dilution buffer or the positive control (hydrogen peroxide) (Fig. 6). Such an ability to quench oxidative stress makes $\mathrm{NH}_{2}-$ AgNPs a biocompatible antibacterial candidate.

AgNPs have been reported to alter homeostasis and membrane permeability in E. coli and Vibrio cholera $^{36}$. In a separate study, Kim et al. ${ }^{37}$ documented AgNPs to form pits within the cell membrane, thereby increasing cell permeability. Research also indicates $\mathrm{Ag}^{+}$ions could inhibit bacteria growth by disrupting DNA replication and inactivating thiol groups in many enzymes ${ }^{36}$. Bruins et al. ${ }^{38}$ suggested that metals could interact with cellular components through covalent and ionic bonding. At higher exposure levels, essential metals including $\mathrm{Co}, \mathrm{Cu}, \mathrm{Ni}$, and $\mathrm{Zn}$ can also inhibit microbial growth and function ${ }^{39}$. Detail characterizations of surface functionalized AgNPs before and after interactions with the $E$. coli cells are paramount to better elucidate how these NPs could elicit toxicity to bacteria and other pathogenic microbes. Employing electron microscopy (Figs. 4-6) coupled with surface spectroscopic techniques (Figs. 3-5, Supplementary Information Fig. S2) allowed us to confirm our in vitro E. coli toxicity results (Fig. 2).

Designing near-atomic size $5 \mathrm{~nm}$ diameter $\mathrm{NH}_{2}$-AgNPs with high positive surface charge is found to be significantly inhibitory to $E$. coli compared to the larger size $45 \mathrm{~nm}$ Citrate-AgNPs with high negative surface charge. The bactericidal effects of $\mathrm{NH}_{2}-\mathrm{AgNPs}$ and the non-toxic effects of Citrate-AgNPs lend credence to the hypothesis that smaller size and highly positive surface charged AgNPs could serve as a next generation antibacterial agent to addressing the growing HAls and patient health and safety.

\section{Conclusions}

AR/MDR is widespread as new AR bacteria and mechanisms are being documented globally, undermining our ability to treat common bacterial diseases using current antibiotics ${ }^{40}$. Addressing HAls due to increasing AR/MDR amongst bacteria is paramount for patient health and safety, and reducing hospital stay and associated health care cost ${ }^{1-3}$. Designing NPs with distinct particle properties allowed us to test the hypothesis that smaller size and highly positive surface charged AgNPs could serve as a next generation bactericidal agent. Our results show that near-atomic size $5 \mathrm{~nm}$ diameter $\mathrm{NH}_{2}-\mathrm{AgNPs}$ with high positive surface charge was significantly inhibitory to $E$. coli compared to the larger size $45 \mathrm{~nm}$ Citrate-AgNPs with high negative surface charge. Further, results showed $\mathrm{NH}_{2}-\mathrm{AgNPs}$ inhibited adherent fimbriae expression and were bactericidal, while $\mathrm{Ag}^{+}$ions were bacteriostatic but led to potentially resistant hexagonal honeycomb-like phenotype in $\mathrm{E}$. coli dh5a. $\mathrm{NH}_{2}-$ AgNPs were also found to quench oxidative stress in human lung epithelium and skin fibroblasts, making it a biocompatible antibacterial candidate. Taken together, this study shows that ENM can be specifically tailored to render higher toxicity 
against the AR/MDR bacteria such as $E$. coli and to mitigate growing HAls as the current antibiotics are losing their efficacy ${ }^{40}$.

\section{Methods}

\section{Synthesis and Purification of Silver Nanoparticles}

Two different types of silver nanoparticles (AgNPs) were synthesized and used in this study: (1) amino $\left(\mathrm{NH}_{2}\right)$-functionalized, positively charged AgNPs $\left(\mathrm{NH}_{2}-\mathrm{AgNPs}\right.$; patent \#PCT/US2021/014343) ${ }^{41}$ of average TEM diameter of $5.8 \mathrm{~nm}$, and (2) citrate-functionalized, negatively charged AgNPs (CitrateAgNPs) of average TEM diameter of $44.8 \mathrm{~nm} .{ }^{12,42}$ All chemicals used in this study were of highest purity and procured from Fisher Scientific. The NPs were synthesized in the laboratory using the protocols that follow: For $\mathrm{NH}_{2}$-AgNPs synthesis, $1 \mathrm{~mL}$ ethyleneimine $(\sim 1 \mathrm{~g})$ and $1.19 \mathrm{~g}$ HEPES were dissolved in Milli-Q water and brought the volume to $500 \mathrm{~mL}$. In a separate flask, $170 \mathrm{mg}$ of silver nitrate $\left(\mathrm{AgNO}_{3}\right)$ and $1.19 \mathrm{~g}$ HEPES were added together, and brought the volume to $500 \mathrm{~mL}$ using Milli-Q water. The contents of both flasks were then added to a liter flask and mixed thoroughly for 30 mins. Using two UV lights $\left(\lambda_{254} \mathrm{~nm}\right)$, the solution was irradiated for $6 \mathrm{~h}$ under constant stirring. The solution was then heated to $90^{\circ} \mathrm{C}$ for 45 mins under constant stirring, then removed from the heat source and added $7.5 \mathrm{mg}$ of borohydride. The suspension was then left at room temperature to cool overnight. Likewise, Citrate-AgNPs were synthesized by adding $1 \mathrm{mM} \mathrm{AgNO}_{3}$ to $10 \mathrm{mM}$ sodium citrate in a volume ratio of $2: 1$. The solution was then heated for $4 \mathrm{~h}$ at $50^{\circ} \mathrm{C}$ in a water bath and was left to cool at room temperature overnight. Upon synthesis, both the NPs were purified using a tangential flow filtration (TFF) system equipped with $3.5 \mathrm{kD}$ hollow fiber polysulfone membranes as we previously described (details in Supplementary Information Table S1) ${ }^{43}$.

\section{Characterization of Nanoparticles}

Transmission electron microscopy (TEM, Philips EM 420, 120 kV, brightfield mode) was used to determine particle size, particle size distribution, and shape of the AgNPs tested. High-resolution Field EmissionScanning Electron Microscopy (FEI Quanta $450 \mathrm{FEG}$ ) was employed for imaging E. coli cell surface morphology and visualizing NP interactions on the $E$. coli surfaces. Samples were drop-casted onto the double-sided adhesive carbon tape attached to the aluminum stub for standard reflective-mode microscopy and onto copper grid with formvar coating for transmissive-mode SEM (STEM), and allowed to dry at room temperature while any excess suspension was absorbed along the edge using a blotting paper. A low vacuum imaging regime $(40-80 \mathrm{~Pa})$ of water vapor was applied during the reflective-mode imaging in order to neutralize potential charging of the samples. E. coli surfaces were then scanned by electron beam using a low accelerating voltage of 3-5 kV for reflective imaging, and $30 \mathrm{kV}$ for transmissive imaging, with a working distance of around $10 \mathrm{~mm}$. Upon EM analysis, energy dispersive spectroscopy (EDS) analysis was performed on the AgNPs and E. coli surfaces for assessing potential nano-bio interactions using AZtec Energy Advanced with X-Max SDD 50 sq mm, 127 eV resolution 
detector (Oxford Instruments). EDS information was collected in three modes: Point mode, ID mode and Mapping mode.

UV-Vis Spectroscopy (Hach DR6000) was used to measure the localized surface plasmon resonance, $\lambda_{\max }$ (maximum wavelength at which the plasmonic peak was observed), of the AgNPs. Hydrodynamic diameters (HDD) of the AgNPs were determined using the dynamic light scattering (DLS; Zetasizer Nano ZS90, Malvern Panalytical) and Smoluchowski equation was used to estimate zeta (ל) potential of the AgNPs based on electrophoretic mobility of the NPs using the $\zeta$ potential software.

\section{Toxicity Bioassay and Treatment Conditions}

E. coli dh5a was used as a model test bioassay. E. coli is a gram-negative bacillus that reproduces by binary fission ${ }^{44}$. Luria-Bertani (LB) medium was used as a culture and growth medium for $E$. coli dh5a. The LB broth constituted: $10 \mathrm{~g}$ peptone, $5 \mathrm{~g}$ yeast extract, and $5 \mathrm{~g} \mathrm{NaCl} .6 .25 \mathrm{~g}$ LB powder was mixed with $250 \mathrm{~mL}$ of ultrapure water in a beaker. The solution was stirred to mix uniformly and autoclaved for 15 min at $121^{\circ} \mathrm{C}$ before use for the bioassay. Four $\mathrm{mL}$ of the prepared LB broth was pipetted into a five $\mathrm{mL}$ centrifuge tube. Then each tube received either $0.5 \mathrm{~mL}$ bacteria $+0.5 \mathrm{~mL}$ water, which served as a negative control; or $0.5 \mathrm{~mL}$ bacteria $+0.5 \mathrm{~mL}$ AgNPs (of each type) as the treatment. Two concentrations, $0.5 \mu \mathrm{g} / \mathrm{mL}$ and $10 \mu \mathrm{g} / \mathrm{mL}$, covering low and high exposure conditions, respectively, were tested for two different types of AgNPs with differing particle sizes, surface charges and coating materials. In addition, we also tested potential impacts of ionic silver $\left(\mathrm{Ag}^{+}\right.$in Milli-Q water) at the same concentrations used for AgNPs $(0.5 \mu \mathrm{g} / \mathrm{mL}$ and $10 \mu \mathrm{g} / \mathrm{mL})$ for comparison. Initial $E$. coli cell density was maintained at $10^{5}-10^{6}$ cells $/ \mathrm{mL}$. Bacteria were then incubated at $37^{\circ} \mathrm{C}$ and population growth was measured as optical density $\left(\mathrm{OD}_{600}\right)$ using UV-Vis spectrophotometer at $600 \mathrm{~nm}$ as a function of time $(0,4,24,48$, and $72 \mathrm{~h})$; experiments were halted at $72 \mathrm{~h}$. Before each measurement, samples were gently vortexed for $3 \mathrm{~s}$ to improve measurement accuracy. Each experiment was repeated twice, and data reported as aggregates. Data were corrected for background absorbance.

Aliquots of E. coli test samples were further used for STEM-EDS analyses to assess AgNP-cell interaction, AgNP localization on the cell surface, cell surface elemental mapping, potential cell damage, and/or morphological alterations in E. coli upon AgNP insult.

\section{Biocompatibility Assay}

Reactive oxygen species (ROS) may be generated upon NP exposure. Lipid peroxidation occurs when excess ROS affects cell membranes and can also lead to oxidation and denaturation of proteins and DNA damage, further inducing inflammatory immune responses and cell death ${ }^{35}$. We tested potential lipid peroxidation (Malondialdehyde [MDA] assay) in human lung epithelial (H-6053; Cell Biologics) and dermal fibroblast (106-05A-1526; Millipore Sigma) cells upon $\mathrm{NH}_{2}-$ AgNPs treatments $(0.05-10 \mu \mathrm{g} / \mathrm{mL})$ to assess its biocompatibility with human cells in vitro as per standard manufacturer's protocol (Abcam; ab118970) ${ }^{45}$. The sample absorbance was read at $532 \mathrm{~nm}$ using a microplate reader. Each 
reaction was performed in triplicate. Sterile water (dilution buffer) was used as a negative control and hydrogen peroxide $(200 \mu \mathrm{M})$ was used as a positive control.

\section{Statistical Analysis}

E. coli morphological dimensions, length and diameter quantified from SEM images using ImageJ were tested for equality of variances using Levene's test before conducting independent samples t-test (2tailed), which tested for significant differences between the treatment sample means and the controls at $p \leq 0.05$ level. Further, using General linear model we tested if cell diameter was a predictor of cell length under different treatment conditions in E. coli. We found that cell diameter could adequately predict cell length in $E$. coli, we then used centroid plot to visualize the distinct $E$. coli clusters based on the overall cell dimensions (length vs. diameter). Statistical analyses were conducted using IBM SPSS (version 16; Chicago, IL, USA).

\section{Quality Assurance}

All containers used in this study were soaked in $5 \% \mathrm{HNO}_{3}$ overnight, cleaned several times using Milli-Q water (18.2 M $\Omega-\mathrm{cm}, \mathrm{TOC}<10 \mathrm{ppb})$, and air dried before use. Electron microscopes are routinely calibrated as part of good laboratory practices.

\section{Declarations}

\section{Acknowledgements}

L.R.P. acknowledges the funding from East Carolina University that partially supported this work (grant \#111101).

Author information

Contributions

L.R.P. conceived and designed the study. L.R.P. led the team, rationally designed and synthesized the AgNPs, contributed to the experimental design, analysis of data, wrote the results and discussion and drew the artwork. Z.L.J. performed the E. coli experiments and wrote the first draft of manuscript. D.D. performed the electron microscopy of the $E$. coli samples and revised the manuscript. S.M.A. performed the oxidative assay, analyzed the data, and revised the manuscript. L.R.P. performed the statistical analysis and revised the manuscript. All co-authors read and approved the manuscript.

\section{Data availability}

The data that support the findings of this study are presented in the main text and the Supplementary Information and are available from the corresponding author upon reasonable request.

\section{References}


1. Alp, E., \& Damani, N. (2015). Healthcare-associated infections in intensive care units: epidemiology and infection control in low-to-middle income countries. Journal of infection in developing countries, 9(10), 1040-1045.

2. Barrasa-Villar, J. I., Aibar-Remón, C., Prieto-Andrés, P., Mareca-Doñate, R., \& Moliner-Lahoz, J. (2017). Impact on Morbidity, Mortality, and Length of Stay of Hospital-Acquired Infections by Resistant Microorganisms. Clinical infectious diseases: an official publication of the Infectious Diseases Society of America, 65(4), 644-652.

3. Mathur P. (2018). Prevention of healthcare-associated infections in low- and middle-income Countries: The 'bundle approach'. Indian Journal of Medical Microbiology, 36(2), 155-162.

4. Pelgrift, R. Y., \& Friedman, A. J. (2013). Nanotechnology as a therapeutic tool to combat microbial resistance. Advanced Drug Delivery Reviews, 65(13-14), 1803-1815.

5. Coque, T. M., Novais, A., Carattoli, A., Poirel, L., Pitout, J., Peixe, L., Baquero, F., Cantón, R., \& Nordmann, P. (2008). Dissemination of clonally related Escherichia coli strains expressing extendedspectrum beta-lactamase CTX-M-15. Emerging Infectious Diseases, 14(2), 195-200.

6. CDC. (2021). List of Selected Multistate Foodborne Outbreak Investigations. https://www.cdc.gov/foodsafety/outbreaks/multistate-outbreaks/outbreaks-list.html

7. Connell, I., Agace, W., Klemm, P., Schembri, M., Mărild, S., \& Svanborg, C. (1996). Type 1 fimbrial expression enhances Escherichia coli virulence for the urinary tract. Proceedings of the National Academy of Sciences of the United States of America, 93(18), 9827-9832. https://doi.org/10.1073/pnas.93.18.9827

8. Spurbeck, R. R., Stapleton, A. E., Johnson, J. R., Walk, S. T., Hooton, T. M., \& Mobley, H. L. (2011). Fimbrial profiles predict virulence of uropathogenic Escherichia coli strains: contribution of ygi and yad fimbriae. Infection and Immunity, 79(12), 4753-4763. https://doi.org/10.1128/IAI.05621-11

9. Stabryla, L.M., Johnston, K.A., Diemler, N.A. et al. (2021). Role of bacterial motility in differential resistance mechanisms of silver nanoparticles and silver ions. Nat.

Nanotechnol. https://doi.org/10.1038/s41565-021-00929-w

10. Franci, G. et al. (2015). Silver nanoparticles as potential antibacterial agents. Molecules 20, 88568874.

11. Duran, N. et al. (2016). Silver nanoparticles: a new view on mechanistic aspects on antimicrobial activity. Nanomedicine 12, 789-799.

12. Silva, T.U., Pokhrel, L.R., Dubey, B., Tolaymat, T.M., Maier, K.J., et al. (2014). Particle size, surface charge and concentration dependent ecotoxicity of three organo-coated silver nanoparticles: General linear model-predicted and observed toxicity. Science of the Total Environment, 468-469:968-976.

13. Yin, L., Cheng, Y., Espinasse, B., Colman, B.P., Auffan, M., et al. (2011). More than the ions: The effects of silver nanoparticles on Lolium multiflorum. Environ. Sci. Technol., 45:2360-7.

14. Park, M.V., Neigh, A.M., Vermeulen, J.P., de la Fonteyne, L.J., Verharen, H.W., et al. (2011). The effect of particle size on the cytotoxicity, inflammation, developmental toxicity and genotoxicity of silver nanoparticles. Biomat., 32(36):9810-7. 
15. Ivask, A., Kurvet, I., Kasemets, K., Blinova, I., Aruoja, V., et al. (2014). Size-dependent toxicity of silver nanoparticles to bacteria, yeast, algae, crustaceans and mammalian cells in vitro. PLoS ONE, 9(7): e102108.

16. El Badawy, A.M., Silva, R.G., Morris, B., Scheckel, K.G., Suidan, M.T., Tolaymat, T.M. (2011). Surface charge-dependent toxicity of silver nanoparticles. Environ. Sci. Technol., 45:283-287.

17. Kim, K-T., Truong, L., Wehmas, L., Tanguay, R.L. (2013). Silver nanoparticle toxicity in the embryonic zebrafish is governed by particle dispersion and ionic environment. Nanotechnol., 24:115101.

18. United States Environmental Protection Agency (USEPA): Chemical Substances When Manufactured or Processed as Nanoscale Materials; TSCA Reporting and Recordkeeping Requirements. 82 FR 22088, May 12, 2017. EPA-HQ-OPPT-2010-0572 FRL-9962-

58. https://www.federalregister.gov/documents/2017/05/12/2017-09683/chemical-substanceswhen-manufactured-or-processed-as-nanoscale-materials-tsca-reporting-and

19. Werner, M., Auth, T., Beales, P. et al. (2018). Nanomaterial interactions with biomembranes: Bridging the gap between soft matter models and biological context. Biointerphases, 13(2).

http://dx.doi.org/10.1116/1.5022145

20. Western Philosophy: William of Ockham. https://www.britannica.com/topic/Westernphilosophy/The-late-Middle-Ages\#ref8657

21. Chakravarty, R. \& Banerjee, P.C. (2008). Morphological changes in an acidophilic bacterium induced by heavy metals. Extremophiles, 12(2), 279-284.

22. Nazzi, F. (2016). The hexagonal shape of the honeycomb cells depends on the construction behavior of bees. Scientific Reports, 6, 28341.

23. Khusro, A., Preetam Raj, J.P., \& Panicker, S.G. (2014). Adaptational Changes in Cellular Morphology of Bacillus subtilis KPA in Response to certain Antimicrobials. International Journal of ChemTech Research, 6(5), 2815-2823.

24. Miyazawa, N., Hakamada, M. \& Mabuchi, M. (2018). Antimicrobial mechanisms due to hyperpolarisation induced by nanoporous Au. Sci Rep 8, 3870. doi:10.1038/s41598-018-22261-5.

25. Yusefi-Tanha, E, Fallah S, Rostamnejadi A, Pokhrel LR. Particle size and concentration dependent inhibition of Copper oxide nanoparticles on seed yield and antioxidant defense system in soil grown soybean (Glycine max cv. Kowsar). Science of the Total Environment 2020, 715:136994.

26. Pogodin, S., Slater, N. K., \& Baulin, V. A. (2011). Surface patterning of carbon nanotubes can enhance their penetration through a phospholipid bilayer. ACS nano, 5(2), 1141-1146.

27. Pogodin, S., \& Baulin, V. A. (2011). Equilibrium Insertion of Nanoscale Objects into Phospholipid Bilayers", Current Nanoscience, 7(5).

28. Vecitis, C. D., Zodrow, K. R., Kang, S., and Elimelech, M. (2010). Electronic-structure-dependent bacterial cytotoxicity of single-walled carbon nanotubes. ACS Nano 4, 5471-5479.

29. Tu, Y., Lv, M., Xiu, P., Huynh, T., Zhang, M., Castelli, M., et al. (2013). Destructive extraction of phospholipids from Escherichia coli membranes by graphene nanosheets. Nat. Nanotech. 8, 594- 
601.

30. Zou, X., Zhang, L., Wang, Z., and Luo, Y. (2016). Mechanisms of the antimicrobial activities of graphene materials. J. Am. Chem. Soc. 138, 2064-2077.

31. Liu, Y., He, L., Mustapha, A., Li, H., Hu, Z.Q., \& Lin, M. (2009). Antibacterial activities of zinc oxide nanoparticles against E. coli 0157:H7. Journal of Applied Microbiology, 107, 1193-1201. doi:10.1111/j.1365-2672.2009.04303.x

32. Raffi, M., Hussain, F., Bhatti, T.M., Akhter, J.I., Hameed, A., \& Hasan, M.M. (2008). Antibacterial Characterization of Silver Nanoparticles against E. Coli ATCC-15224. Journal of Material Science and Technology, 24(2), 192-196.

33. He, Y., Ingudam, S., Reed, S., Gehring, A., Strobaugh, T.P., \& Irwin, P. (2016). Study on the mechanism of antibacterial action of magnesium oxide nanoparticles against foodborne pathogens. Journal of Nanobiotechnology, 14:54, 1-9.

34. Li, H., Chen, Q., Zhao, J., \& Urmila, K. (2015). Enhancing the antimicrobial activity of natural extraction using the synthetic ultrasmall metal nanoparticles. Nature - Scientific Reports, 5:1103, 113. doi: $10.1038 /$ srep 11033

35. Zhang, Z., L. Rong, and Y.P. Li, Flaviviridae Viruses and Oxidative Stress: Implications for Viral Pathogenesis. Oxid Med Cell Longev, 2019: p. 1409582.

36. Morones, J.R., Elechiguerra, J.L., Camacho, A., Holt, K., Kouri, J.B., Ramirez, J.T., \& Yacaman, M.J. (2005). The bactericidal effect of silver nanoparticles. Nanotechnology, 16(10), 2346-2353. doi:10.1088/0957-4484/16/10/059

37. Kim, J.S., Kuk, E., Yu, K.N., Kim, J., Park, S.J., et al. (2007). Antimicrobial effects of silver nanoparticles. Nanomedicine: Nanotechnology, Biology, and Medicine, 3, 95-101. doi:10.1016/j.nano.2006.12.001

38. Bruins, M.R., Kapil, S., \& Oegme, F.W. (2000). Microbial resistance to metals in the environment. Epidemiology and Environmental Safety, 45(3), 196-207.

39. Olaniran, A.O., Balgobind, A., Pillay, B. (2013). Bioavailability of Heavy Metals in Soil: Impact on Microbial Biodegradation of Organic Compounds and Possible Improvement Strategies. Int. J. Mol. Sci., 14, 10197-10228.

40. World Health Organization (WHO). (2020). Antibiotic Resistance. https://www.who.int/newsroom/fact-sheets/detail/antibiotic-resistance

41. Pokhrel, L.R. (ECU). (2021). Nanotechnology-based Pesticides and Intermediates, Compositions and Treatments Using the Same." International Patent Application No. PCT/US2020/014343.

42. Pokhrel, L.R., Dubey, B., Scheuerman, P.R. (2014). Natural water chemistry (dissolved organic carbon, $\mathrm{pH}$, and hardness) modulates colloidal stability, dissolution kinetics and antimicrobial activity of silver nanoparticles. Environmental Science: Nano, 1:45-54.

43. Pokhrel, L.R., Andersen, C.P. (2015). SOP for Purification of Engineered Nanoparticles Using the Tangential Flow Filtration (TFF) System. National Health and Environmental Effects Research 
Laboratory, Western Ecology Division, USEPA, OR. January 2015, Pages 1-12. DCN: EEB/CA/2015-01$\mathrm{r} 0$.

44. Kenyon College Department of Biology. (2015). DH5-Alpha E. coli. Microbe Wiki. Retrieved from: https://microbewiki.kenyon.edu/index.php/DH5-Alpha_E.coli

45. Luo, M., Wu, L., Zhang, K., Wang, H., Zhang, T., Gutierrez, L., et al. (2018). miR-137 regulates ferroptosis by targeting glutamine transporter SLC1A5 in melanoma. Cell Death Differ 25:1457-1472.

\section{Tables}

Table 1. Impacts of differential surface charge of two AgNPs types on nano-bio interactions and toxicity in E. coli dh5a.

\begin{tabular}{|c|c|c|c|c|c|c|}
\hline \multirow[t]{3}{*}{ Samples } & \multicolumn{2}{|c|}{$\begin{array}{l}\text { Mean Zeta } \\
\text { potential }^{a}(\mathrm{mV})\end{array}$} & \multirow{3}{*}{$\begin{array}{l}\text { Magnitude of } \\
\text { charge difference }^{b} \\
|A-B|\end{array}$} & \multirow[t]{3}{*}{$\begin{array}{l}\text { Strength of } \\
\text { interaction }\end{array}$} & \multirow[t]{3}{*}{$\begin{array}{l}\text { Expected } \\
\text { toxicity }\end{array}$} & \multirow[t]{3}{*}{$\begin{array}{l}\text { Observed } \\
\text { toxicity }\end{array}$} \\
\hline & Day-0 & Day-3 & & & & \\
\hline & & $\begin{array}{l}(w / E . \\
\text { coli) }\end{array}$ & & & & \\
\hline E. coli & -14.8 & $-10.0^{c}$ & 4.8 & na & na & na \\
\hline $\begin{array}{l}\text { Citrate- } \\
\text { AgNPs }\end{array}$ & -30.0 & -15.0 & 15.0 & $\begin{array}{l}\text { Lower } \\
\text { electrostatic } \\
\text { attraction }\end{array}$ & Lower & Lower \\
\hline $\begin{array}{l}\mathrm{NH}_{2}- \\
\text { AgNPs }\end{array}$ & +41.6 & -17.0 & 58.6 & $\begin{array}{l}\text { Higher } \\
\text { electrostatic } \\
\text { attraction }\end{array}$ & Higher & Higher \\
\hline
\end{tabular}

aZeta potential measured in test media (LB broth).

${ }^{b}$ Magnitude of charge difference is presented as an absolute value.

cMinor change in zeta potential of control samples (E. coli + LB broth) over $72 \mathrm{~h}$ period.

'Cit-AgNPs' denotes citrate-functionalized AgNPs; ' $\mathrm{NH}_{2}$-AgNPs' denotes amino-functionalized AgNPs. 'na' denotes not applicable.

Table 2. Toxicity of different AgNPs types on cell wall, adherent fimbriae expression, and shape change in E. coli dh5a. Significant effects are shown in bold. 


\begin{tabular}{|lllll|}
\hline Test chemical & Concentration & Cell damage & Fimbriae & Shape \\
\hline Control & 0 & No & Present & Rod \\
\hline Cit-AgNPs & $0.5 \mu \mathrm{g} / \mathrm{mL}$ & No & Present & Rod \\
\hline $\mathrm{NH}_{2}-$ AgNPs & $0.5 \mu \mathrm{g} / \mathrm{mL}$ & Yes & Absent & Rod \\
& $10 \mu \mathrm{g} / \mathrm{mL}$ & All dead & Absent & All dead \\
\hline $\mathrm{Ag}^{+}$ions & $0.5 \mu \mathrm{g} / \mathrm{mL}$ & Yes & Present & Rod \\
\hline & $10 \mu \mathrm{g} / \mathrm{mL}$ & No & Absent & Hexagonal honeycomb \\
\hline
\end{tabular}

Figures 

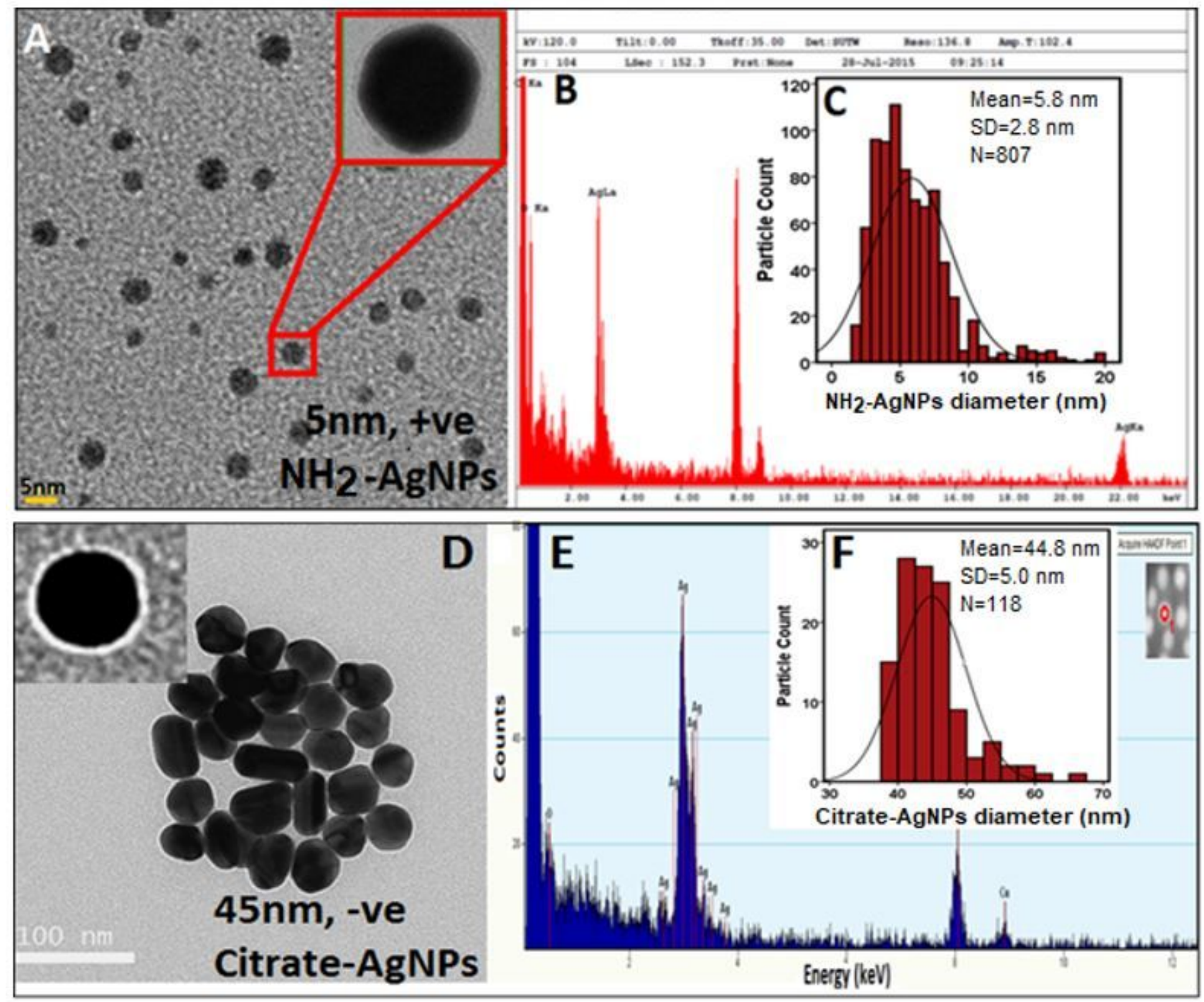

Figure 1

Transmission electron microscopy (TEM) image (A), Energy dispersive spectroscopy (EDS) (B), and particle size distribution (PSD) (C) analysis of $5 \mathrm{~nm}$ diameter, positively charged polyethyleneiminefunctionalized silver nanoparticles (NH2-AgNPs). TEM image (D), EDS (E), and PSD (F) analysis of 45 $\mathrm{nm}$ diameter, negatively charged Citrate-functionalized silver nanoparticles (Citrate-AgNPs). 

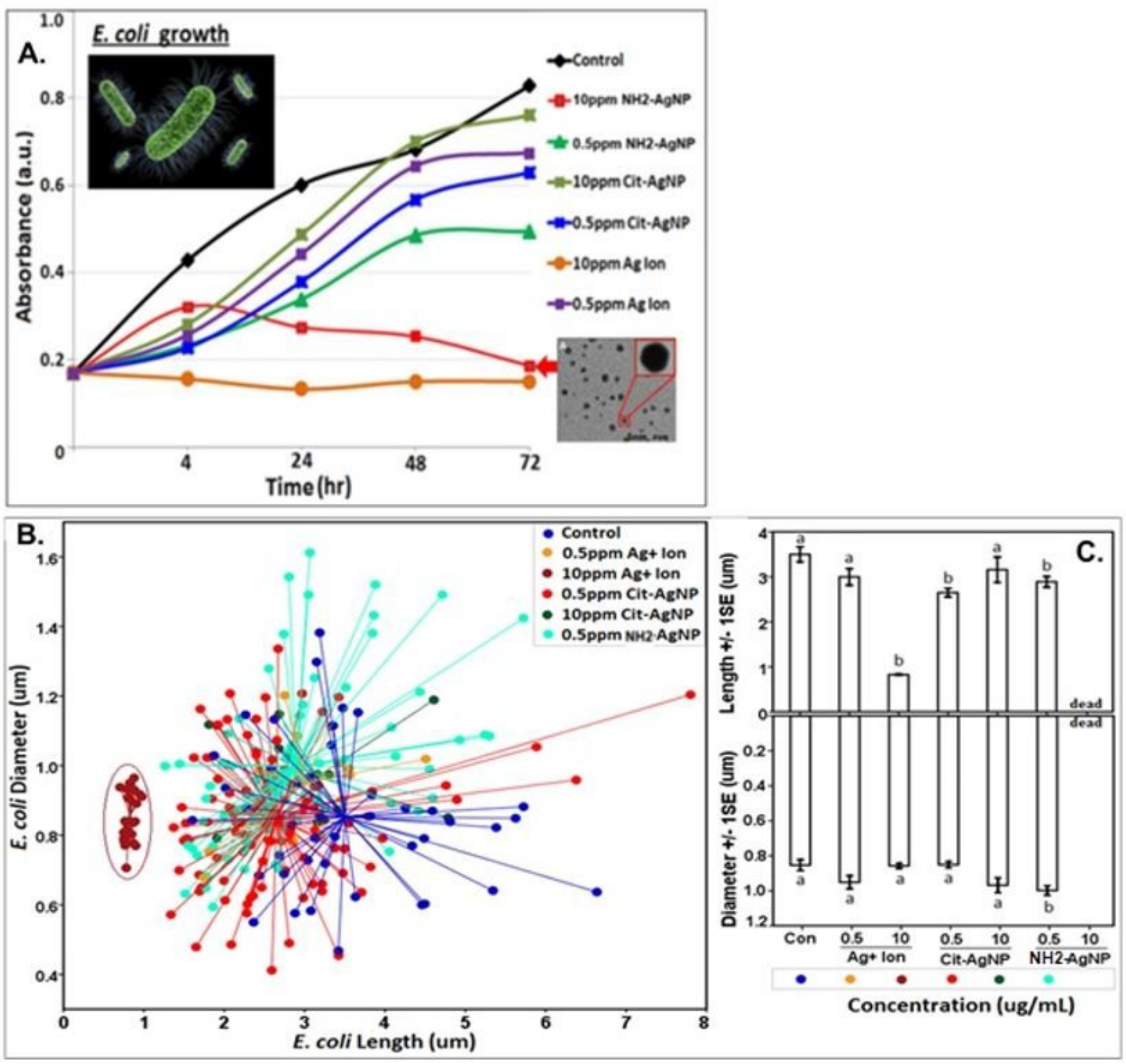

Figure 2

Variation in E. coli growth under different treatment conditions and incubated at $37^{\circ} \mathrm{C}$ over a period of 72 h. Treatment data were corrected for background absorbance. Ag+ ions showed bacteriostatic effect at $10 \mu \mathrm{g} \mathrm{Ag} / \mathrm{mL}$; NH2-AgNPs showed bactericidal effect at $10 \mu \mathrm{g} \mathrm{Ag} / \mathrm{mL}$, while other treatments led to increased growth of bacterial population as a function of time (A). E. coli diameter (Y-axis) plotted against its length (X-axis) depicting morphological alterations in body size under different treatment conditions (B); each data point is connected to the centroid showing discrete morphological clusters under different treatments (B). Significant variation in bacterial cell length and diameter were tested using two-tailed t-test at $p \leq 0.05$ (C). Same letter above the bar indicates no significant difference between the 
sample means. Corresponding SEM images of the E. coli cells upon different silver treatments are presented in Fig. 3.

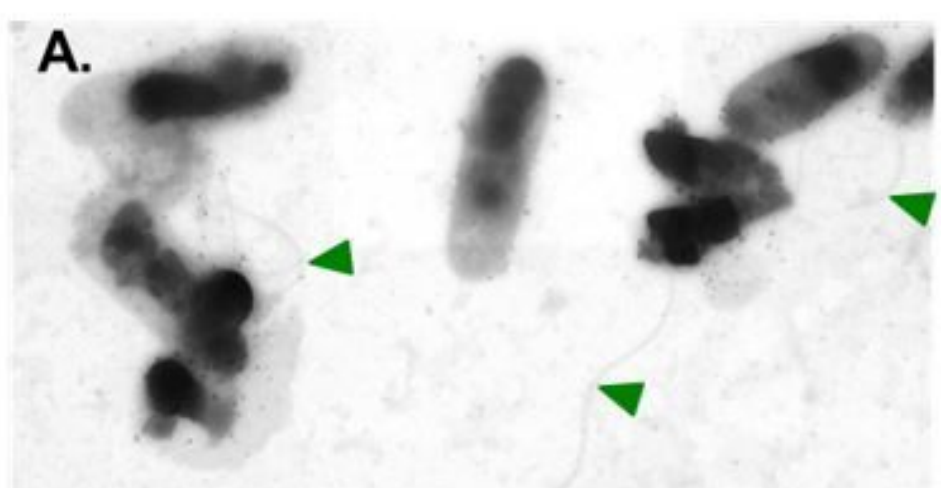

\section{Control}

C.

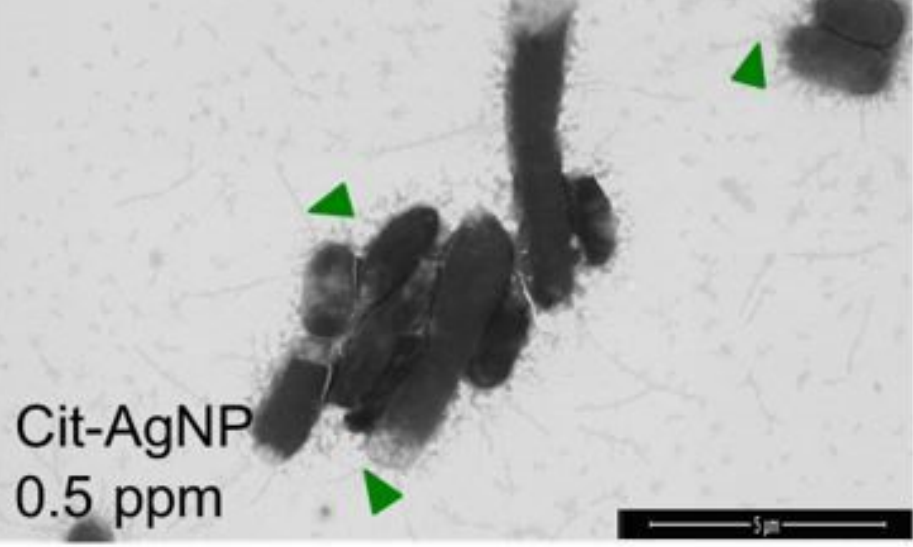

E.

$\mathrm{Ag}+$ ions

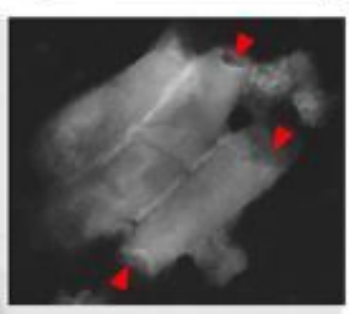

Cit-AgNP $10 \mathrm{ppm}$

\section{$\mathrm{NH}_{2}-\mathrm{AgNP}$}

$0.5 \mathrm{ppm}$

D.

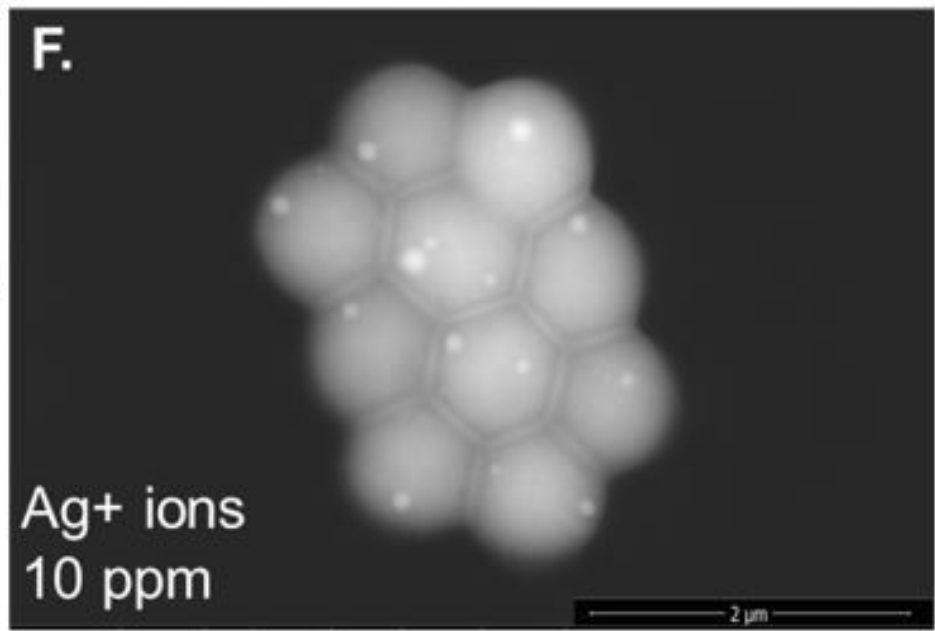

\section{Figure 3}

Representative Field Emission-Scanning Electron Microscope (FE-SEM) images of E. coli dh5a imaged after 72 hours of exposure to different Ag treatments: (A) Control; (B) NH2-AgNPs, $0.5 \mu \mathrm{g} / \mathrm{mL}$; (C) CitAgNPs, $0.5 \mu \mathrm{g} / \mathrm{mL}$; (D) Cit-AgNPs, $10 \mu \mathrm{g} / \mathrm{mL}$; and (E) Ag+ ions, $0.5 \mu \mathrm{g} / \mathrm{mL}$; and (F) Ag+ ions, $10 \mu \mathrm{g} / \mathrm{mL}$. Note, $\mathrm{NH} 2-$ AgNPs at $10 \mu \mathrm{g} / \mathrm{mL}$ treated cells are not shown as no bacteria could be located under the FE- 
SEM after 72 hours because the cells were likely disintegrated and dissolved upon exposure. Green triangle denotes adherent fimbriae being expressed, and red triangle denotes cell wall damage. 'ppm' denotes parts per million, equivalent to $\mu \mathrm{g} / \mathrm{mL}$.

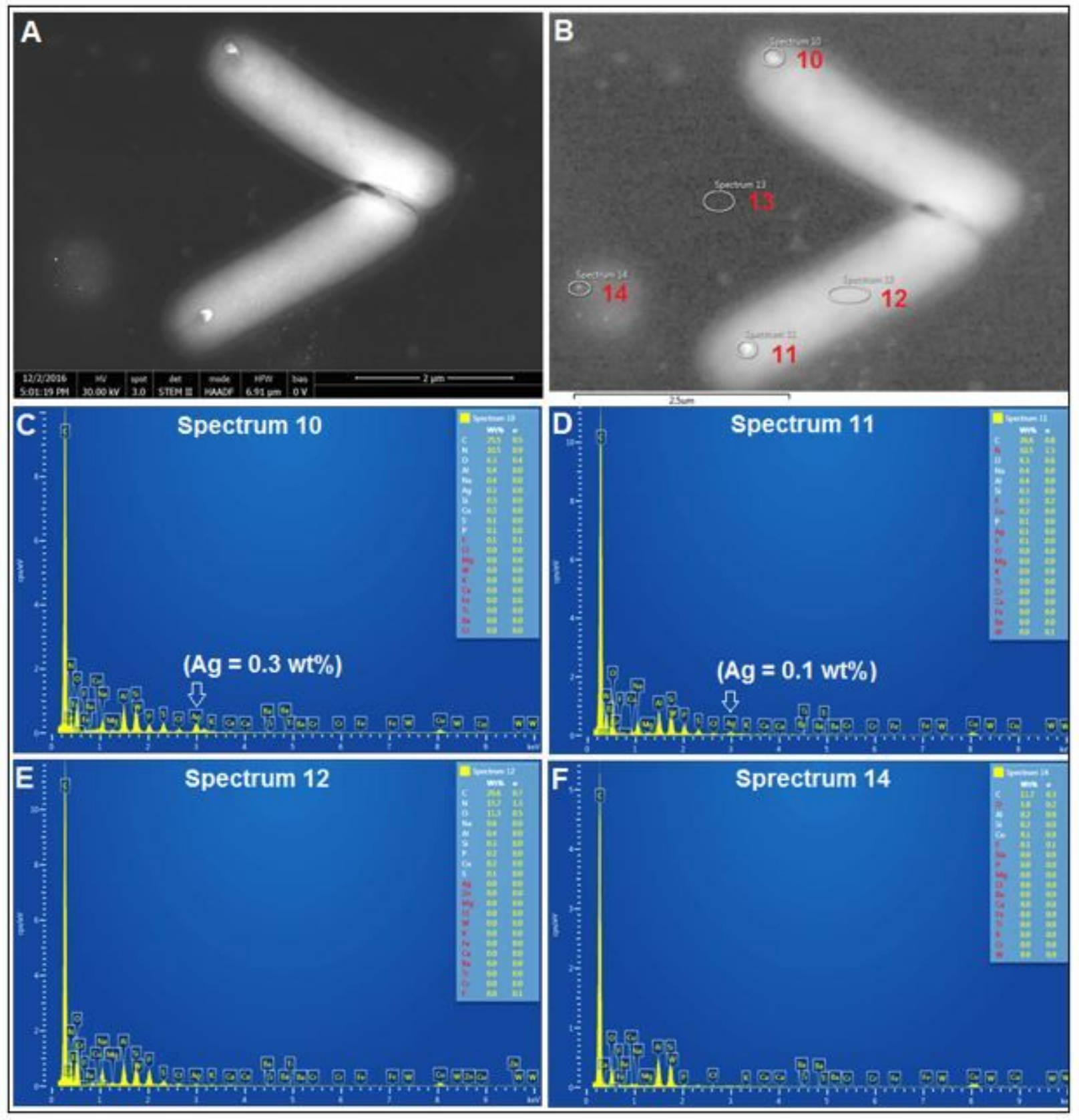

\section{Figure 4}

Field Emission-Scanning Electron Microscopy (FE-SEM) analysis of E. coli morphology upon exposure to $10 \mu \mathrm{g} / \mathrm{mL}$ PEl-AgNPs for 10 mins (A,B) revealed a larger nanoparticulate of Ag (size range 155-157 nm in diameter) at the end of each cell surface. EDS spectra (spectra \#10-14) of Ag across the selected areas on E. coli surfaces were recorded (C-F), which confirmed that the nanoparticulates observed at the end of cells were composed of elemental $\mathrm{Ag}(\mathrm{C}, \mathrm{D})$. 


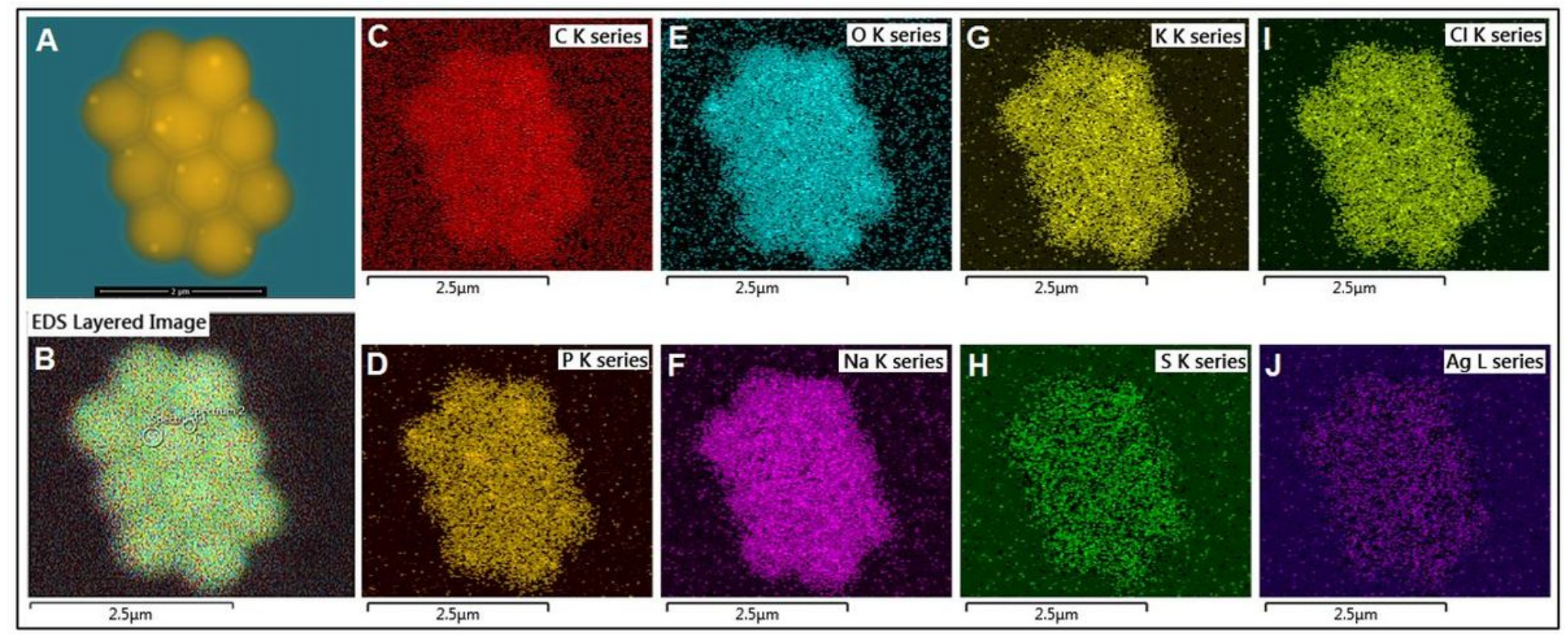

\section{Figure 5}

Energy dispersive spectroscopy (EDS) elemental mapping of silver on E. coli dh5a surfaces upon exposure to $10 \mu \mathrm{g} / \mathrm{mL}$ Ag+ ions for 72 hours. Scale bar denotes $2.5 \mu \mathrm{m}$ for all images, except for A (scale bar $=2 \mu \mathrm{m})$. 


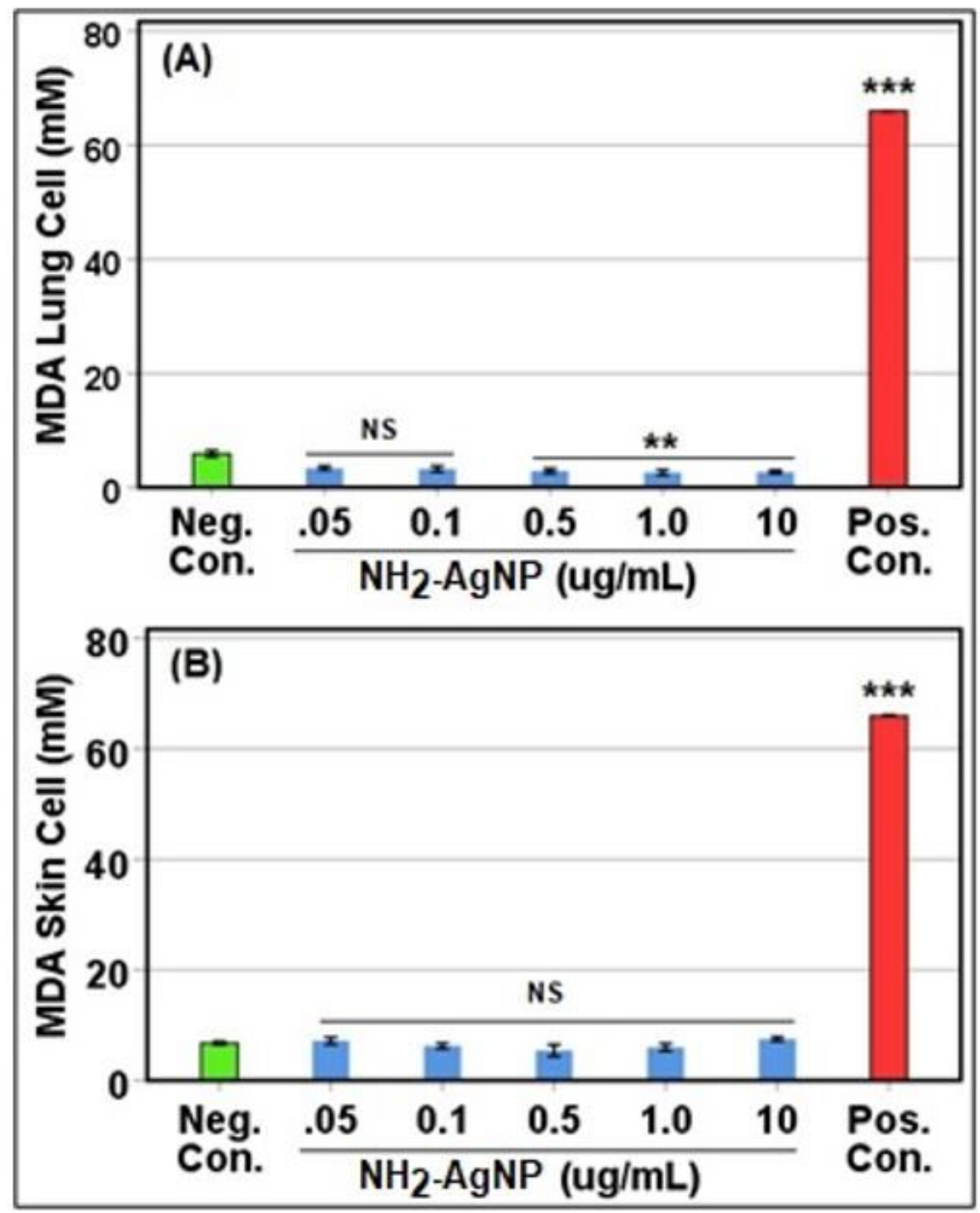

Figure 6

In vitro oxidative stress response of NH2-AgNPs in primary human lung epithelial cells $(A)$ and dermal fibroblast cells (B), showing no Malondialdehyde (MDA) lipid peroxidation in both cell assays. ' ${ }^{*}$ ' denotes

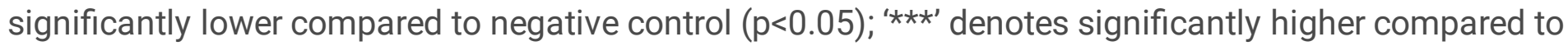
negative control $(p<0.001)$; and NS, denotes each treatment group is not significantly different from negative control ( $p>0.05)$. Negative control denotes diluent buffer (sterile water), and Positive control denotes hydrogen peroxide $(200 \mu \mathrm{M})$.

\section{Supplementary Files}

This is a list of supplementary files associated with this preprint. Click to download. 
- SupplementaryInformationPokhreletal2021.docx 